\title{
Study on Temperature Characteristics of Ice-covered Conductors during Ice-melting
}

\author{
Daxing WANG ${ }^{1,2, a}$, Bin HE $\mathrm{HE}^{1,2, b}$, Shoubao LIU1,c, Tianxiang HU², , Wei Zhonge,e, \\ Tingbin $\mathrm{LI}^{2, \mathrm{f}}$, Wenhao $\mathrm{LI}^{2, \mathrm{~g}}$ \\ ${ }^{1}$ State Grid Sichuan Electric Power Research Institute, Chengdu, China \\ ${ }^{2}$ Sichuan Tong Yuan Electric Power Science \& Technology CO.,LTD, Chengdu, China

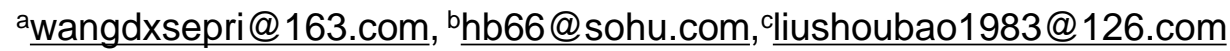

\begin{abstract}
Keywords: temperature characteristics, ice-melting, transmission line
Abstract. Ice-melting with short-circuit in transmission line is the most effective methods of de-icing. Conductor would be damaged if rapidly rising conductor temperature exceeds the allowable temperature. Therefore, study on temperature characteristic of conductor in the process of ice-melting ensure effective ice-melting and not to damage the wire in ice-melting process. Combined with the thermal ice-melting with short-circuit current balance of during ice-melting, mathematical and physical model of ice melting was established, the influencing rule of a variety of factors on the maximum temperature of conductor was also analyzed. In addition, the method to calculate the maximum temperature of conductor was put forward.
\end{abstract}

\section{Introduction}

Power transmission line is the main part of power network, transmission line icing is a serious threat to security and stability of power system operation, it can cause transmission lines overload, conductor galloping and insulator string flashover, thus may seriously endanger the safety of power system operation ${ }^{[1-5]}$. Because of ice disaster frequently occurring, dozens of methods have been proposed to anti-icing and de-icing by power department. So far, no method can be used to prevent the ice disaster of transmission lines effectively except short-circuit ice-melting method.

The research and application of ice-melting have a long history, the former Soviet Union have used the measure of ac ice-melting since 1950s, China have started using ac ice-melting since 1976, Manitoba Water and Power Authority in Canada has studied on dc short circuit ice-melting since 1993. The ice-melting of transmission line has been studied widely in the world, and many models have been proposed to calculate the ice-melting time ${ }^{[6-8]}$, but relatively large error has presented between the results calculated by existing models and the actual engineering application. The analysis show, the reason of the error is that all existing ice-melting models assume that the temperature of conductor surface maintain at $0^{\circ} \mathrm{C}$ during ice-melting. But actual measurement and analysis show that temperature of conductor is higher than $0^{\circ} \mathrm{C}$ because of the effect of water film and air gap caused by ice-melting.

In the process of ice-melting, wire temperature will rise rapidly due to Joule heat generated by the large current, thus may exceed the maximum temperature (The present standards require that the maximum temperature of conductor should not exceed $+70^{\circ} \mathrm{C}$ in China). The mechanical strength and the impact of life of conductor, as well as electric power fittings will be affected in varying degrees due to over high temperature ${ }^{[9]}$.

Thus this paper analyzes on the maximum temperature of conductor and its influencing factors. Through theoretical analysis and experimental verification, the reasonable selection of the ice-melting current is the key of ice-melting in the condition of the temperature of conductor within the allowable temperature. In this way, ice-melting current will not damage conductors so as to make power system operation safe and stable. 


\section{Physical and mathematic model of ice-melting}

It is assumed that the wire is infinitely long and the icing of wires is the uniform cylindrical glaze ice. When the current pass through the conductor, the conductor is heated by joule heat, then the heat is transferred to ice layer. The outer surface of ice and air exchange the heat by convection and radiation. Hence, the temperature of conductor surface is the highest, the temperature gradually descends throughout the ice layer during ice-melting. When the surface temperature of conductor is higher than $0^{\circ} \mathrm{C}$, the ice contacted with the conductor begins to melt. In the process of ice-melting, the inner surface of the ice is the mixture of ice and water which maintains at $0^{\circ} \mathrm{C}$. The water loss through the ice porosity, thus there forms the uneven distribution of the air gap between the ice and the conductor. The ice layer gradually shifts down under gravity, and the air gap under the conductor increases gradually. In this paper, experiment results show the air gap (including the wire) is similar to oval shape, as shown in Figure 1.

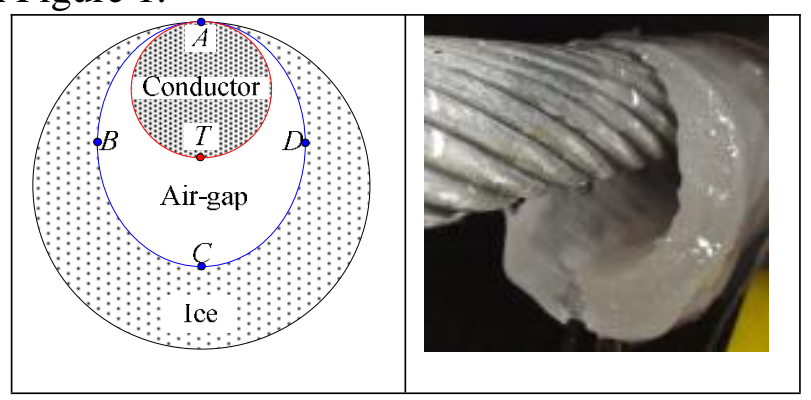

Figure 1 Schematic diagram of cross-section during ice-melting

The thermal conductivity in the process of ice-melting is heat transfer from conductor to ice layer due to temperature gradient between the ice and conductor. Because the conductor is long enough, temperature gradient in the axis direction can be neglected. $R_{\mathrm{c}}$ and $D_{\mathrm{i}}$ are conductor radius and the thickness of ice respectively; $r_{\mathrm{T}}$ is the conductor resistance when the temperature of the conductor is $\mathrm{T}$; and $\lambda$ is thermal conductivity that can be considered to be constant. $T(\theta)$ is the temperature of conductor surface, in which $\theta$ is shown in Figure 1. $T_{\mathrm{w}}$ is the temperature of inner surface of ice layer constituted by region of ABCD. $l(\theta)$ is the distance of $\theta$ corresponding the conductor surface to the inner surface of ice layer. Ice layer begins to melt, there is the state of the mixture of ice and water in inner surface of ice, the temperature keeps constant at $0^{\circ} \mathrm{C}$, that is expressed by

$$
\left.T_{w}\right|_{A B C D}=0
$$

$q$ is the ice-melting power per unit cross-section area $\left(\mathrm{W} / \mathrm{m}^{2}\right)$, it can be formulated as follows:

$$
q=\frac{I^{2} r_{T}}{\pi R_{c}^{2}}
$$

According to Fourier law, the heat transfer equation is

$$
q=\lambda \frac{T(\theta)-T_{w}}{l(\theta)}
$$

According to boundary conditions (1), equation (4) can be formulated by equation (3) as follow

$$
T(\theta)=\frac{q l(\theta)}{\lambda}
$$

As is shown in Figure $1, l(\theta)$ is less in the near surface of conductor, while $l(\theta)$ is larger near the undersurface of conductor, so the distribution of $l(\theta)$ is uneven, the temperature distribution of surface conductor $T(\theta)$ is also uneven through equation(4). When ice-melting current is determined, $T(\theta)$ increases with increasing $l(\theta)$. The temperature of surface conductor reaches the maximum when $l(\theta)$ become maximum, as is shown in Figure $1 \mathrm{~T}$ point.

In the process of ice-melting, the ice will be detached from the conductor under its own gravity when the contact angle between ice and conductor is $0^{\circ}{ }^{[6]}$. Since the air gap becomes larger with the increasing ice thickness, the superficial area which the conductor contacts with air also increases, so does the thermal resistance of the conductor, thus joule heat speeds up the temperature of conductor rising. When the ice is just falling from the conductor, the air gap will reach the maximum, that is to 
say, $l(\theta)=D_{\mathrm{i}}$ (T point in Figure 1). So the temperature of conductor reaches to the maximum at the moment.

Steady-state heat transfer equation of "Conductor-Interface of ice layer" is

$$
\int_{0}^{2 \pi} \lambda R_{\mathrm{c}} \frac{T(\theta)}{l(\theta)} d \theta=I^{2} r_{T}
$$

So the function of surface temperature of conductor $T(\theta)$ is obtained

$$
T(\theta)=f(l(\theta), I)
$$

When the $T(\theta)$ is $T_{\max }$, the relationship of $T_{\max }$ is as following

$$
T_{\max }=f\left(D_{i}, I\right)
$$

That is to say $T_{\max }$ is not affected by wind velocity and ambient temperature, but is determined by the thickness of ice and ice-melting current.

\section{Numerical simulation of temperature characteristic of conductor}

Lead early in the ice melting, the temperature gradually increases, there is a non-steady state process. With the march of time, the temperature of various points changes, heat gradually reach to dynamic equilibrium at last. That is, heat from the wire is equal to its distribution, when the highest temperature reaches in the process of ice melting. After reaching equilibrium, heat flow and temperature fields do not change over time, it can be considered the wire and the temperature of air space and other regional issues as a heat source of two-dimensional steady state heat transfer problems, which need to use the steady-state heat conduction differential equation with heat source.

Steady temperature field of conductor is isotropic and two-dimensional steady state heat conduction within the heat source. A heat source region (such as wire) temperature control equation can be simplified as equation (8):

$$
\frac{\partial^{2} T}{\partial x^{2}}+\frac{\partial^{2} T}{\partial y^{2}}+q_{v}=0
$$

In equation, $T$ is the temperature of point $(\mathrm{x}, \mathrm{y}),{ }^{\circ} \mathrm{C} ; q$ is volumetric heating rate, $\mathrm{W} / \mathrm{m}^{3}$.

No heat source region (such as ice, air gap, etc.) temperature control equation can be simplified as equation (9):

$$
\frac{\partial^{2} T}{\partial x^{2}}+\frac{\partial^{2} T}{\partial y^{2}}=0
$$

Established a conductor temperature thermal conductivity equation, solve the equation according to the boundary conditions.

By Galerkin method of the weighted residual method, equation (8) is solved as ${ }^{[10]}$

$$
\left[\begin{array}{llll}
k_{11} & k_{12} & \mathrm{~L} & k_{1 n} \\
k_{21} & k_{22} & \mathrm{~L} & k_{2 n} \\
\mathrm{~L} & \mathrm{~L} & \mathrm{~L} & \mathrm{~L} \\
k_{n 1} & k_{n 2} & \mathrm{~L} & k_{n n}
\end{array}\right]\left[\begin{array}{l}
T_{1} \\
T_{2} \\
\mathrm{~L} \\
T_{n}
\end{array}\right]=\left[\begin{array}{l}
p_{1} \\
p_{2} \\
\mathrm{~L} \\
p_{n}
\end{array}\right]
$$

Finally, the temperature of every point temperature value can obtained by the iterative method or the Gaussian elimination method solved equation (10).

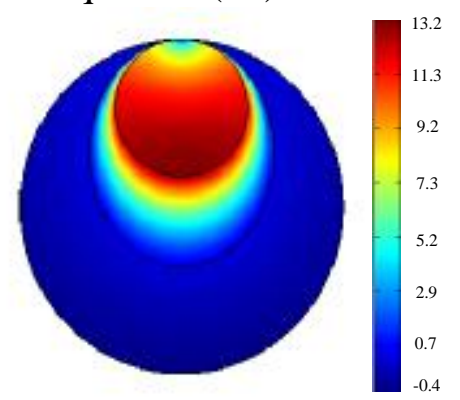

Fig.2 Temperature Profile of Solution Domain 


\section{Experimental verification of temperature characteristic of conductor and influence factor}

In order to verify the correctness of the model and influencing the maximum temperature factors, experiments are carried out in multi-function artificial climate chamber with the diameter of $7.8 \mathrm{~m}$ and the height of $11.6 \mathrm{~m}$. The dc ice-melting power can supply current as high as 5000A.

The temperature of conductor surface is measured by DS18B20 temperature sensor produced by DALLAS Company. The measuring range of temperature is $-55^{\circ} \mathrm{C}+125^{\circ} \mathrm{C}$ and its accuracy is $\pm 0.5^{\circ} \mathrm{C}$. Wind velocity is measured by using hand-held anemometer. Ambient temperature is measured with the PTU 2000 pressure-temperature-humidity transmitter. The measurement accuracy of temperature at $20^{\circ} \mathrm{C}$ is $\pm 0.2^{\circ} \mathrm{C}$.

In view of transmission lines of different voltage levels used in China, in this paper, one kind of conductor LGJ-240/30 was adopted in experiment (The length of test conductors was $3 \mathrm{~m}$ ). The technical parameters are shown in table 1, which $r_{20} 、 r_{\mathrm{T}}$ are the rate of resistance corresponding with $20^{\circ} \mathrm{Cand} T^{\circ} \mathrm{C}$ respectively, the conversion relationship is following

$$
r_{T}=r_{20}[1+\alpha(T-20)]
$$

Where $\alpha$ is temperature coefficient of resistance of aluminum, at $3.6 \times 10^{-3} /{ }^{\circ} \mathrm{C}$.

Table 1 The technical parameters of conductors

\begin{tabular}{cccc}
\hline Conductor type & $D_{\mathrm{i}} / \mathrm{mm}$ & $D_{f e} / \mathrm{mm}$ & $r_{20} /(\Omega / \mathrm{m})$ \\
\hline LGJ-400/35 & 27.63 & 6.90 & $0.07389 \times 10-3$ \\
\hline
\end{tabular}

The uniform cylindrical glaze ice of conductor is simulated in multi-function artificial climate chamber, and ambient temperature is controlled by the refrigeration equipment, the fan is used to change wind velocity in the range of $0 \mathrm{~m} / \mathrm{s} \leq v_{\mathrm{a}} \leq 5 \mathrm{~m} / \mathrm{s}$. In this paper, the experiment adopts the method of dc ice-melting, experimental circuit is shown in Figure 3.

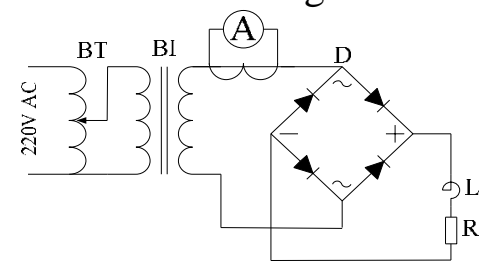

Figure 3 Experiment circuit (D: Bridge Rectifier; L: smoothing Reactor; R: sample Resistance; BT: Regulator; BI: Transformer) 
Table 2 The maximum temperature $T_{\max }$ and $T_{\text {max }}$ in the process of ice-melting

\begin{tabular}{cccccc}
\hline$I / \mathrm{A}$ & $D_{\mathrm{i}} / \mathrm{mm}$ & $t_{\mathrm{e}} /{ }^{\circ} \mathrm{C}$ & $v_{\mathrm{a}} /(\mathrm{m} / \mathrm{s})$ & $T_{\max } /{ }^{\circ} \mathrm{C}$ & $T^{\prime}{ }_{\max } /{ }^{\circ} \mathrm{C}$ \\
\hline 800 & 7.2 & -3.0 & 5.0 & 8.9 & 9.2 \\
800 & 9.0 & -3.0 & 4.0 & 9.2 & 9.5 \\
800 & 9.8 & -3.0 & 1.0 & 9.3 & 9.7 \\
800 & 10.0 & -3.0 & 5.0 & 9.3 & 9.7 \\
800 & 11.3 & -7.0 & 5.0 & 9.7 & 9.9 \\
800 & 13.4 & -7.0 & 3.0 & 10.0 & 10.6 \\
800 & 14.0 & -7.0 & 1.0 & 10.1 & 10.7 \\
800 & 15.0 & -1.0 & 4.0 & 10.3 & 11.1 \\
800 & 16.5 & -1.0 & 5.0 & 10.5 & 11.2 \\
850 & 8.0 & -5.0 & 1.0 & 10.2 & 10.5 \\
850 & 8.5 & -5.0 & 1.0 & 10.3 & 10.5 \\
850 & 10.0 & -5.0 & 3.0 & 10.7 & 11.3 \\
850 & 12.8 & -1.0 & 3.0 & 11.2 & 11.9 \\
850 & 15.0 & -3.0 & 3.0 & 11.5 & 12.3 \\
900 & 10.0 & -5.0 & 2.0 & 11.9 & 12.7 \\
900 & 14.9 & -5.0 & 2.0 & 12.8 & 13.2 \\
950 & 10.0 & -5.0 & 3.0 & 13.3 & 14.1 \\
1000 & 15.0 & -5.0 & 3.0 & 15.8 & 16.8 \\
\hline
\end{tabular}

It is known from Table 2 that before critical state of ice layer shedding, the inner surface of ice (region of $\mathrm{ABCD}$ ) is the mixture of ice and water, the temperature of which is $0^{\circ} \mathrm{C}$. In this condition, changes in wind velocity and ambient temperature only affect the speed of ice-melting. The maximum temperature of the conductor (the temperature of point $\mathrm{T}$ ) is not affected by conditions outside the closed interval which is constituted by region of ABCD.

Analysis shows that the thickness of ice and ice-melting current on the maximum temperature is independent of each other. Hence, the maximum temperature of conductor $T_{\max }$ can be expressed by the thickness of ice $\left(D_{\mathrm{i}}\right)$ and ice-melting current $(I)$, such as equation (11):

$$
T_{\max }=K D_{i}^{m} I^{n}
$$

Where $K$ is characteristic coefficient of the sample conductor; $m$ is the characteristic index of the maximum temperature of conductor $T_{\max }$ with the thickness of ice $D_{\mathrm{i}} ; n$ is the characteristic index of the maximum temperature of conductor $T_{\max }$ with ice-melting current $I$.

Equation (11) is treated by mean of the linearization process:

$$
\ln T_{\max }=\ln K+m \ln D_{i}+n \ln I
$$

According to least square method, as long as the guarantee of square of deviance $M$ is the smallest, absolute deviation between test data and the results of equation (12) is extremely small.

$$
M=\sum_{i=0}^{n}\left[\ln T_{\max i}-\left(\ln K-m \ln D_{i}-n \ln I\right)\right]^{2}
$$

Where $M$ is square of deviance; $T_{\max i} 、 D_{\mathrm{i}}$ and $I$ are the maximum temperature of conductor, the thickness of ice and ice-melting current respectively in Table 2.

$M$ is a ternary function of independent variables $K$ and $m$ as well as $n$, when the function $M=M(K, m, n)$ obtains the minimum value, $K 、 m$ and $n$ are determined, so it can be integrated the expression equation of $T_{\max }$.

The minimum point of square of deviance $M$ can be obtained by calculation for extreme value of multivariate function. Equation (14) can be obtained by solving the partial derivative equations of equation (13) available, and it is formulated as follows:

$$
T_{\max }=1.67 \times 10^{-5} I^{2} D_{i}^{0.17}
$$

According to engineering practice, this calculation formula can give certain guidance to select ice-melting current to guarantee for the conductor in normal working state. 


\section{Conclusion}

(1) The distribution of the temperature of conductor surface is uneven during ice-melting, where the conductor relatively close contact with the ice, the temperature maintain at $0^{\circ} \mathrm{C}$; The temperature of the undersurface of conductor increases with increasing air gap. The conductor reaches to the highest temperature when the ice is falling from the conductor.

(2) During dc ice-melting the maximum temperature of conductor is determined by the thickness of ice and ice-melting current, and is not influenced by ambient temperature and wind velocity.

(3) Simulation and test data is more consistent with the overall trend. As the experiment of ice melting takes longer time and test environment and equipment require exact demands, we can sum up the law through a large number of simulation.

\section{References}

[1] JIANG Xingliang, Yi Hui. Transmission line's icing and its protection [M]. Beijing, China Electric Power Press, 2002.

[2] HU Yi. Analysis and Countermeasures Discussion for Large Area Icing Accident on Power Grid [J]. High Voltage Engineering, 2008(34):215-219.

[3] C. Yangchun, N. Chunjie and L. Chengrong. The reliability evaluation method of high voltage overhead transmission lines[C]. 2008 International Conference on Condition Monitoring and Diagnosis, pp. 566-569, 2008.

[4] JIANG Xingliang. Transmission lines' ice accidents and analysis of the formative factors [J]. Electric Power, 2005, (11).

[5] JIANG Xingliang, ZHANG Lihua. De icing and Anti icing of Transmission Lines [J]. High Voltage Engineering, 1997, (01).

[6] J.V.C.Vargas, A. Bejan and A. Dobrovicescu. The melting of an ice shell on a heated horizontal cylinder[C]. Transactions of the ASME. Journal of Heat Transfer, 1994(116):702-708.

[7] Michel Landry, Roger Beauchemin, AndréVenne. De-icing EHV overhead transmission lines using electromagnetic forces generated by moderate short-circuit currents[C].Proceedings of IEEE 9th International Conference on Transmission and Distribution Construction, Operation and Live-line Maintenance.2000:94-100.

[8] K.H.Hesse. Ice melting systems in Manitoba hydro [M].Canadian Electrical Association, Montreal, QC,Canada, Mar,1998.

[9] M.Huneault, C.Langheit,and J.Caron. Combined models for glaze ice accretion and de-icing of current-carrying electrical conductors[J] IEEE Transactions on Power Delivery, 2005(20):16111616.

[10] Chen Shaoxin, WuPei-sheng. Application of On-line Temperature and Sags Monitoring Device of Transmission Line [J]. North China Electric Power, 2008,3: 14-15. 